\title{
Perceptions and Thirst for Knowledge Regarding Hypertension among Rural Dwellers in Isunjaba, Imo State, Nigeria: A Qualitative Study
}

\section{Eunice Ogonna Osuala ${ }^{1}$, Abimbola Oyenihum Oluwatosin ${ }^{2}$, Felix Ngozichukwuka Osuala ${ }^{3}$, Sally Nkechinyere Onyeka Ibe ${ }^{4}$}

${ }^{1}$ Department of Nursing Science, Nnamdi Azikiwe University, Nnewi, Nigeria

${ }^{2}$ Department of Nursing, University of Ibadan, Ibadan, Nigeria

${ }^{3}$ Department of Pharmacognosy, Faculty of Pharmacy, Madonna University, Elele, Nigeria

${ }^{4}$ Department of Public Health, Federal University of Technology, Owerri, Nigeria

Email: *euniceosuala@yahoo.com

How to cite this paper: Osuala, E.O., Oluwatosin, A.O., Osuala, F.N. and Ibe, S.N.O. (2016) Perceptions and Thirst for Knowledge Regarding Hypertension among Rural Dwellers in Isunjaba, Imo State, Nigeria: A Qualitative Study. Health, 8, 1603-1615. http://dx.doi.org/10.4236/health.2016.814157

Received: August 20, 2016

Accepted: November 22, 2016

Published: November 25, 2016

Copyright $\odot 2016$ by authors and Scientific Research Publishing Inc. This work is licensed under the Creative Commons Attribution International License (CC BY 4.0).

http://creativecommons.org/licenses/by/4.0/

\section{(c) (i) Open Access}

\begin{abstract}
Hypertension accounts for $13 \%$ of global mortality, is one of the most frequent causes of end stage kidney failure in the world, and has a $25 \%$ prevalence in Nigeria. Primary prevention based on comprehensive population-based intervention has been found most economical. Lifestyle modification is an essential part of management. It is important for the researcher to have a deep understanding of people's perceptions and attitudes to diseases like hypertension where effective interventions must address lifestyle choices of community members. Thus, this descriptive qualitative study carried out among 48 rural dwellers between ages 20 and 75 in Isunjaba, Imo state, to determine their perception and attitude to hypertension issues. Information gathered would be used in creating intervention programme to prevent hypertension and promote health. Findings revealed that participants were aware of incidents of sudden deaths and stroke in the town. There was a strong belief among members that hypertension "can be sent by one's enemy", even though majority attributed it to "worries and much thinking". Unhealthy lifestyles such as alcohol, and stimulant consumption (kolanut and snuff) were elicited. Daily activities were said to be equivalent to regular exercise. Participants were eager for measures to prevent hypertension and curb the incidence of stroke in the communities. There is therefore the need to institute hypertension awareness and blood pressure monitoring programme in the community.
\end{abstract}

\section{Keywords}

Perception, Attitude, Hypertension, Health Promotion, Rural Dwellers 


\section{Introduction}

Hypertension has been recorded as a major type of cardiovascular disease, said to affect one billion people worldwide [1], predicted to increase to 1.56 billion by 2025 [2] and claims the life of seven million annually [3]. The disease, based on data on death certificate, accounts for $13 \%-16.5 \%$ percent of global mortality [4] [5] [6]. One in three (between 28\% and 31\%) adults in the United States of America has hypertension [7]. According to Danbauchi [8] and Okeahialam [9], hypertension is a major cause of morbidity and mortality among Nigerians and is accompanied by complications such as stroke, retinopathy, diabetes, cardiac and renal failure [10]. The prevalence of hypertension in Nigeria with a population of 1 million [11] was between $20 \%$ and $25 \%$ according to Danbauchi [8]. However a study in Port Harcourt, South-South of Nigeria reported a prevalence of $40.82 \%$ among the study participants [12].

By casual observation, cases of stroke and sudden deaths have been noted in Isunjaba in Isu Local Government Area of Imo State. These cases may be linked to cardiovascular diseases (CVD). There is a need for investigation and control. Effective intervention will depend on accurate information. The opinion and belief of the people will guide the development of the tool for a quantitative study. The most appropriate method to extract the opinion and beliefs of the people on hypertension, the commonest CVD is Focus Group Discussion (FGD), hence this study. The FGD format consists of 7 openended questions that guided the discussion, eliciting information on: socio-cultural issues, knowledge, attitude and lifestyle patterns as well as suggestions from participants.

This was designed by the researcher and reviewed by experts in the field for the purpose of extracting relevant information from the participants (Appendix 1-attached). Through the FGD sessions, the perception and attitude to hypertension prevention and lifestyle habits of the community were assessed. The perception of the rural dwellers on risk factors, symptoms, management, prevention, and complications of hypertension as well as attitude to the disease was elicited. The information gathered was used to develop the tool for a quantitative study in the community in order to achieve the goal of an intervention.

\section{Methods}

Two out of four autonomous communities (named E and C), in Isunjaba Imo State were selected by balloting. Purposive sampling method was adopted to make sure age criteria and both sexes were equally represented. Population size was guided by Focus Group Discussion principle on appropriate number. Participants were grouped into three, based on their ages: 20 - 40, 41 - 60 and 61 and above, and referred to as groups 1,2 and 3 respectively. Each group was made up of eight participants. Six groups of eight people each; comprising 48 within the ages of 20 and 75 formed the focus groups. Summary of Focus Group Discussions (FGD) placement is shown in Table 1. Participation was voluntary. Thus, an individual aged 20 - 40 who resides in community E is referred to in this report as an individual in group 1E. The three age groups were 
Table 1. Summary of Focus Group Discussions (FGD) placement.

\begin{tabular}{|c|c|c|c|c|}
\hline Number & \multicolumn{2}{|c|}{ Experimental Group } & \multicolumn{2}{|c|}{ Control Group } \\
\hline \multirow{2}{*}{8 each } & Men & Women & Men & Women \\
\hline & \multicolumn{2}{|c|}{$20-40$ years } & \multicolumn{2}{|c|}{$20-40$ years } \\
\hline \multirow{2}{*}{8 each } & Men & Women & Men & Women \\
\hline & \multicolumn{2}{|c|}{$41-60$ years } & \multicolumn{2}{|c|}{$41-60$ years } \\
\hline \multirow{2}{*}{8 each } & Men & Women & Men & Women \\
\hline & \multicolumn{2}{|c|}{$61-75$ years } & \multicolumn{2}{|c|}{$61-75$ years } \\
\hline
\end{tabular}

homogeneous based on age grade among community members. Community opinion leaders assisted in identifying the various age grades. Each group comprised of both males and females (as the topic high blood pressure is not gender sensitive), equal in number selected using purposive sampling method. The focus group discussions in each community were held the same day, though at different times and settings for convenience. Appointments were made well before the day. There were six sessions in all. There were morning, afternoon and evening sessions. The oldest set had their seating in the evenings while the youngest group had theirs in the afternoons. The setting was the chosen parlour of a member of each group. Two separate days served for the exercise with their market days in consideration. Before commencement, informed consent was obtained from the respective community leaders and each participant who ensured that inclusion was based on the age grade system in the community. This is to gain the cooperation of the community leaders and for ethical consideration. Semi structured interview guide was employed in the exercise. Each sitting lasted for approximately one hour. Researchers had two assistants; a recorder and a note taker, whose notes taken were compared with audiotapes, and transcribed on the same day of the event. The demographic data was coded and summarized under frequencies and percentages using SPSS soft ware package, Version 20. Age of participants was grouped into three categories before the coding. Recorded FGD information was transcribed and summarized using proportions and themes based on investigated variables.

\section{Results}

Demographic data showed that the 48 participants comprised of 24 males and 24 females. There were 16 (33.3\%) participants in each of the 3 age groups. Only 4 (8.3\%) had tertiary education while majority had primary education. Forty-four (91.6\%) were Christians while Muslims and traditional religious worshippers were 2 (4.2\%) respectively. Thirty-four (70.8\%) were married, 12 (25.0\%) single and 2 (4.2\%) divorced. Under occupation $18(37.5 \%)$ are jobless, civil servants $6(12.5 \%)$, trading $10(20.8 \%)$ and farming $14(29.2 \%)$. None was on high income of N100, 000 naira and above in a month. Ten (20.8\%) were on average income of N20,000 - N100,000 while 38 (79.2\%) were on low income below N20,000 a month (Table 2). Responses from participants were arranged under subheadings based on investigated variables. Several participants 
Table 2. Socio demographic characteristics of respondents: $\mathrm{N}=48$.

\begin{tabular}{|c|c|c|}
\hline Variable & Frequency & $\%$ \\
\hline \multicolumn{3}{|l|}{ Sex } \\
\hline Male & 24 & 50 \\
\hline Female & 24 & 50 \\
\hline \multicolumn{3}{|c|}{ Educational Qualification } \\
\hline Tertiary & 4 & 8.3 \\
\hline Secondary & 16 & 33.3 \\
\hline Primary & 20 & 41.7 \\
\hline Non formal & 8 & 16.7 \\
\hline \multicolumn{3}{|l|}{ Age } \\
\hline $20-40$ & 16 & 33.3 \\
\hline $41-60$ & 16 & 33.3 \\
\hline $61-75$ & 16 & 33.3 \\
\hline \multicolumn{3}{|l|}{ Religion } \\
\hline Christianity & 44 & 91.6 \\
\hline Moslem & 2 & 4.2 \\
\hline Traditional & 2 & 4.2 \\
\hline \multicolumn{3}{|l|}{ Marital Status } \\
\hline Married & 34 & 70.8 \\
\hline Single & 12 & 25.0 \\
\hline Divorced & 2 & 4.2 \\
\hline \multicolumn{3}{|l|}{ Occupation } \\
\hline Jobless & 18 & 37.5 \\
\hline Civil Servant & 6 & 12.5 \\
\hline Trading & 10 & 20.8 \\
\hline Farming & 14 & 29.2 \\
\hline \multicolumn{3}{|l|}{ Income } \\
\hline High & 0 & 0 \\
\hline Average & 10 & 20.8 \\
\hline Low & 38 & 79.2 \\
\hline
\end{tabular}

described incidents of sudden death and stroke in the community, and these events have shaped the way community members think about hypertension. In the words of one participant "hypertension is attack from the enemy! Can't you see how that lady teacher's corpse was found in her farm and the other from next village slumped in the bathroom? It is sent by one's enemy through the air". There was a strong believe among members that hypertension can be sent by one's enemy even though some attributed it to worries and much thinking. Adoption of unhealthy lifestyles such as alcohol abuse, and stimulant consumption-(kolanut and snuff) were elicited. Daily activities were said to be equivalent to regular exercise. Participants expressed their eagerness for adoption of healthy lifestyle measures to prevent hypertension and curb the incidence of 
stroke in their respective communities. Findings showed readiness for health seeking behavior among the participants.

Attitude and perception of participants on the various questions were similar in both communities though some differences in opinion were elicited from the group aged 20 - 40. Seven themes evolved from the data: level of awareness of predisposing factors, knowledge of disease, attitude to and perception on susceptibility and seriousness of disease, risk prone behaviours and lifestyle habits, perceived benefits of prevention and possible barriers, enabling factors in the community, as well as recommendations on the way forward.

Theme 1: Awareness of predisposing factors

Members of the various groups were aware of incidents of sudden death or stroke in their communities, and even gave instances. Every participant agreed to having heard of hypertension, and the groups generated varied local names for the disease, such as high blood pressure, attack from spirit and fast killer. The 20 - 40 year age group in both communities said hypertension is a disease of old people that cannot occur in young people. When asked about the perceived age of onset of hypertension, a man in group 3C stated that "hypertension is from 40 years and above". All participants in the 20 - 40 year age group showed enthusiasm for being included in the programme, but held strongly to the belief that hypertension is not a disease of the young but for the older generation. There were questions from participants such as: "Can a young person really be affected?" came from a male in Group 2C, looking sober with palm supporting chin. One male participant from group $1 \mathrm{E}$ innocently chipped in, "How can I have hypertension when I am always happy, having good time with my beautiful girls and dancing my popular dance steps for youngsters in the East. The rest of the group burst out in laugher. Another concurred saying, "He is right, beautiful girl friend is the in thing". "Anyway tell us about this disease of old people in case we can help them" chipped in a $3^{\text {rd }}$ male in the group. "Will you teach us how to check this blood pressure?" asked one of the females in the group. The researcher promised that such can be arranged later. "Is any particular sex affected more by hypertension?", asked yet another.

Yes! responded many. Hypertension is more common in women. The responses came more from the women than men. Participants, when asked if cases of sudden deaths or stroke have been observed in their community by anybody? A chorused "Yes!" in a high pitched voice was echoed by participants. An instance was described by a woman in group $2 \mathrm{E}$, while another came from a man in group $3 \mathrm{C}$. The description of these instances suggested that community members are perplexed about the events in their communities. When asked if any participant had anybody with hypertension in their families, there was no response. Has anyone been told in a hospital that he/she is hypertensive? Only one woman in group $2 \mathrm{E}$ nodded her head. Further discussions revealed that no one knew what the normal blood pressure reading should be, even the woman in group $2 \mathrm{E}$ that nodded her head that she is hypertensive. A remark in a harsh voice came from a male in the Group "It is like everyone is hypertensive, what brought this problem into our mist? People of old were not having it". "Can it be avoided?", a woman in the same Group asked in a low tone. The researcher reassured her that it can 
be prevented, and controlled if one develops it.

Theme 2: Knowledge of disease

What is hypertension? In each group 6: 8 had the correct answer. They knew it is sustained high blood pressure. Participants gave three local names for hypertension as "obara mgbali elu" (high blood pressure) "Mba agbara" (attack from spirits) and "Ogbu mgwa mgwa" (fast killer). What value is termed "hypertension"? Only one person out of all the groups got it right. Some claimed they used to know the normal value in the past and question on the normal value was thrown back on the researchers. What is the cause? Answers such as "much thinking, eating too much foo foo and ancestral spirits" were provided. How would hypertension be diagnosed? A woman in $2 \mathrm{C}$ and two men in $2 \mathrm{E}$ and $3 \mathrm{E}$ respectively stated that it is with instrument tied on the arm (Sphygmomanometer). None in the groups could pronounce the name. A man in $3 \mathrm{E}$ chipped in that one can recognize an individual with hypertension by the facial expression as face will appear stern. None knew the symptoms, risk factors and preventive measures. Knowledge of complication was good as majority echoed "stroke" in response.

Theme 3: Attitude to and perception of disease

Susceptibility: All the participants perceived hypertension as serious, but believed they would not develop it in their lifetime, with the exception of the woman in group $2 \mathrm{E}$. When asked, "Is it possible you may have hypertension in your life time?", responses were abrupt. "Tufiaakwa! (never!) it is not me", “God forbid!", “It is not my portion!”, "My fore fathers will not allow such evip" and "I reject it in Jesus name" were some of the responses gathered, accompanied by shrugging of the shoulders, spitting and using the middle finger and thumb to demonstrate rejection.

Seriousness: All participants in communities $\mathrm{E}$ and $\mathrm{C}$ perceived hypertension as a very serious disease. "Bikonne" (please my sister) referring to a member of the research team, "tell us how we can avoid it" chipped in a woman participant from Group 2E, and others chorused "yes". "Let her come and teach us in August meeting" (referring to a regular women's meeting held every August in the Eastern part of the Country), continued the woman. "No!" shouted the male participants in the group "it should be in our hall, do we attend August meeting with you?" The researcher assured them that a progamme will be arranged to provide awareness and also check their blood pressure in due course.

Myths regarding hypertension:

There were misconceptions regarding the cause of hypertension, the setting for management and even method of prevention. Hypertension or stroke, some believed, could be sent to a victim through Juju (mystical means), remote control, enemy attack, food poisoning, knock on the head by spirits though more than half said it could be from what we eat. Majority believed that treatment is better in hospitals by orthodox doctors while some said it is better treated in churches by priests. All believed that there is total cure for hypertension. Five participants, from Groups 3E and $3 \mathrm{C}$ said it can only be prevented through "strong" prayers (intercessors). Majority of participants said the cause is known while 6 said it is unknown. When probed regarding the possible causes, all participants in Group 1 claimed that they did not know. In Groups 2 and 3, the re- 
sponse was different. “Man! Evil men!”, shouted a man in Group 3 of C. Others concurred. When probed to find out if the respondent meant his fellow men, there was a chorus answer. "Yes". Thereafter, a man in group 3C narrated how one of his kinsman vowed to send stroke to another man from the next village and accomplished the same within a month. "What of Mr. A. M.", chipped in another man in the group "Did you not hear his story? This man of God in town Pastor $A$ was the one that revealed that the "attack" was from his rich cousin at Onitsha, Chief O. Nurse, my daughter, things happen in this our town". The woman next to him chipped in "End time". Participants in Group 3E believed evil spirits caused hypertension. In Groups 2E and 2C, half had the same opinion as participants in Group 3, while the other half stated that the disease was caused by what we eat.

Theme 4: Risk prone behaviours/Lifestyle habits

Worrying was said to be the main cause of hypertension by many participants. Older respondents in Groups 3E and 3C, i.e. 61 - 80 years old respondents were in agreement with this thought. In the words of one older participant, "much thinking was said to be the main leading risk factor". Many risk behaviors such as alcohol consumption, use of tobacco products, stimulants and table salt, fatty foods, lack of regular exercises, lack of rest and lack of medical checkup were elicited when lifestyle habits of participants were discussed. Statements such as "We have heard of Shnapp, Whisky and our local Gin as being harmful, do you mean taking beer and stout can also be injurious to health?" were made. Participants were asked to share their opinions on what they thought could bring about hypertension, i.e. in relation to habits and the things they eat.

"On lifestyles; Yes! Lack of rest, eating too much cassava (akpu), salt, alcohol and snuff can bring about this disease" were some of the responses from various groups. Four people in group 3; 2 each in $\mathrm{E}$ and $\mathrm{C}$ respectively said they would be dead without snuff. One man in $\mathrm{C}$ said that alcohol and snuff work together to keep the body in a good state. "What do you think is keeping we old ones agile?", asked a participant in the same group. There was laughter. "Whether one takes these stuffs or not, this high blood pressure has been injected into the air and can affect anybody.", chipped in another. "It is good you have come to address the matter. Please help us to tell your Government at Abuja" (cut short by another member), "No! She said they are from Ibadan!" The former speaker continued, (clears his throat) "wherever they sent them from, this lady (pointing) is government herself, tell Government to look into the issues of bad sight and arthritis after this one." A woman in the group added, "it is like the two has also been injected into the air". Another round of laughter followed as two other female participants in the group shook their heads in agreement. One of the 2 women that nodded in agreement to the last contribution then asked, "What of the disease for sugar? All of them need to be addressed by the Government!"

Participants did not mention any risk factor of hypertension. In order to extract information on risk factors in relation to food question on food habit was asked in general terms. When asked what they usually consume in their respective communities in terms of food, drinks and habits, a lively discussion followed on food habits. It was ga- 
thered that "akpu" (cassava foo foo) is consumed a lot.A lot of vegetable is consumed, though the method of preparation varied among participants. Kolanut is consumed by many. Snuff and cigarette consumption was elicited among all groups, though use of snuff was rare amongst the youngest participants (Group 1), but two smokers were identified. The women participants stated that they preferred offal to "mortuary" (fresh) fish because it is cheaper and more tasty. Fruits were said to be scarce and expensive as the trees that bear fruits are hewn down for houses and electric poles to be put in place. There were varied opinions on use of table salt. About a quarter of the participants said they had been told in one August meeting to desist from the practice. One man in group $3 \mathrm{E}$ asked, "are we in the civil war again that we should eat 'obunnoo'?" (salt free diet). Use of bullions in soup is common among the various groups. "Any soup without maggi is tasteless" chipped in a woman from Group 2C. The other three women in the group nodded their heads in agreement. Indomie with fried egg was upheld as the best menu by three quarters of the Group 1 participants.

The discussion on exercise as a predisposing factor for hypertension generated responses that portrayed ignorance. Daily chores were mistaken as regular exercises by all. A member in group 2E, emphasized this point by saying, "Hm! You people live in town. Car takes you to all places". Another chipped in "from air conditioned car to air conditioned room". There was laughter. The former continued "going up and down in the house, farming, trekking to church and answering to "ekwe" and "ogene" (instruments used by town criers) in this town is even more than any exercise! We do not need any more exercise?' The conversation dug deeper to explore sources of stress. It was unanimously agreed by all group members that there is a lot of stress in families and the entire community, but God sees them through. Examples of stressors were given as communal conflicts, series of meetings that usually end very late at night, levies, poverty, unemployment, resulting in emotional distress, and land disputes among family members.

Theme 5: Perceived benefits of prevention and possible barriers

All participants believed that prevention is better than cure and majority indicated readiness to adopt health promotion measures that can prolong life. Group 2 participants were more eager to know the preventive measures than those in groups 1 and 3. Noted barriers to taking known preventive measures include finance, as many were not ready to allow the meager family income to be spent on tools for blood pressure measurement. Some in Group 3 complained of the distance to the health centers and saw age as a limitation to regular visits for blood pressure checks and regular exercise, such as cycling and brisk walking.

Theme 6: Enabling factors in community

It was elicited from various groups that they have primary health care centers with government trained nurses where those who are sick go to access health services. Time to access health is not a problem, but as far as participants were concerned, relatively healthy people have nothing to do with health centers and hospitals. A participant in Group 2C stated that health workers are like policemen, "once you go to them they 
must detect a disease as policemen will detect fault in a car. Going for a health checkup will create anxiety and fear". Another participant in 1C concluded the issue by saying, "wetin concern Agboro (bus loader) with over load?" This means that it is only a sick person that needs a doctor, as he perceives himself free from hypertension based on his age.

Theme 7: Recommendations by participants

Participants' suggestions were summarized as:

1. Researchers should come home and teach them more often

2. Solicit with government for:

-Creation of blood pressure centers in each kindred,

-Provision and distribution of blood pressure apparatus to each kindred,

-Same should be left in the custody of respective leaders,

-Establishment of mobile blood pressure checks by Local Government Chairman,

-Provision of transport and fund for such programmes.

\section{Discussion}

Findings showed there was poor knowledge of hypertension even though participants have heard of hypertension and have witnessed cases of stroke. This may be due to their level of education as only 4 (8.3\%) attained tertiary education being a rural community. It is also in line with the findings of studies conducted by researchers in Nigeria, Africa and America. In the study by Osuala et al. responses on awareness of incidents of stroke and sudden deaths in the community was 88 (73.3\%) each while average knowledge was $40(33.3 \%)$ [13]. Ike et al. stated that $50 \%$ of their patients thought that hypertension was caused by stress [14]. In a meta- analysis on hypertension awareness and prevalence by Atakelte et al. in which 33 surveys were reviewed between 2000 and 2013, only 23 (30\%) was aware of their hypertension status before survey [15]. Ford and Kim in a purposive study sample of 25 African-American women aged 40 - 74, who lived in rural Alabama and participated in seven Talking Circles for 60 minutes, felt that hypertension was a "common occurrence" and it was "typical in the African American community [16]. These findings reflect poor knowledge even though participants are aware of the term "hypertension".

Attitude of participants in this study revealed disbelief that they could be victims of hypertension in their lifetime as it is termed not their "portion" unlike in a cross sectional survey on 525 staff of a University in Nigeria (Ibadan) by Ige et al. in which 37 (7\%) considered themselves at risk for developing new/additional Non-Communicable Disease (Hypertension inclusive) [17].

Myths and misconception were marked in line with the study by Osuala et al. in which participants stated that hypertension is sent by enemy and stroke caused by ancestors [13]. Some of the participants in this study contributed in the discussion that hypertension does not affect young people and is more in men. Ekunkunbor's findings is also similar to this as he stated that like many other diseases, there are certain misconception often held by some people; that hypertension is not a problem for women yet reports show that it is the leading cause of death for women over 65 years [18]. This 
implies that majority may not readily avoid risk factors, thus portraying a negative attitude. Eagerness for prevention of hypertension was portrayed in this study through the concerns raised by participants as they perceived hypertension as a serious health problem in line with the study at Owerre-Nkwoji, Imo State, Nigeria where 52 (43.3\%) agreed that hypertension is of serious health concern. Twenty (16.7\%) strongly agreed and $52(43.3 \%)$ agreed that it is important to check one's blood pressure regularly even though $16(13.3 \%)$ strongly agreed and $36(30.0 \%)$ agreed that hypertension is not for young people [13].

Lifestyle of the people like consumption of their cassava foo foo as staple food was elicited. The hassles of life were termed exercise. This may be because very few are civil servants. Unhealthy lifestyles elicited include use of alcohol, table salt and stimulants as in the studies by Aghaji [19] and Iyalomhe [20]. High fat intake and salt has been established as risk factors in hypertension meanwhile healthy food choices can actually lower blood pressure [21]. This can be achieved through community-oriented nursing by creating partnerships with individuals, families, groups, and communities to promote their heath using the community health nursing process model [22].

\section{Limitation}

Liberal use of local language was hindered by international nature of the publication. The limited number of participants does not allow for generalization of the findings. A quantitative study and replication of the study in other communities in the State and other States of the nation is being recommended.

\section{Conclusion}

Focus Group Discussion remains an essential tool gathering of information on opinions and beliefs of individuals [23]. Participants in the study were between the ages of 20 and 75. Majority were aware that hypertension is the same as sustained high blood pressure. Participants responded that there are increased incidents of stroke and sudden death in the community. A major complication of hypertension is stroke as revealed by the responses of the participants. This was in line the findings of Salako [10]. Negative attitude to risk factors was mainly identified amongst those lower than 41 years and was more common in males than females. It therefore implies that even though any age can be affected, prevention package should target most vulnerable group which in this case are the youths especially males. Information was used to develop questionnaire and development of tool in planning health promotion strategies. The myths about hypertension are of serious concern. Similar myths and misconceptions were identified in the studies on hypertension and breast cancer in Nigeria [13] [24]. There is a need for awareness programme to address misconceptions.

\section{Recommendation}

In order to reduce the incidence of hypertension and its sequel, it is being recommended that information from this study guide in planning health promotion strategies 
with emphasis on correction of myths and misconceptions about hypertension in rural communities in Nigeria using Community Health Nursing Process Model.

\section{References}

[1] Mittal, B.V. and Singh, A.K. (2010) Hypertension in the Developing World: Challenges and Opportunities. American Journal of Kidney Diseases: The Official Journal of the National Kidney Foundation, 55, 590-598. http://dx.doi.org/10.1053/j.ajkd.2009.06.044

[2] Thomas, D., Meera, N.K., Binny, K., Sekhar, M.S., Kishore, G. and Sasidharan, S. (2011) Medication Adherence and Associated Barriers in Hypertension Management in India. CVD Prevention and Control, 6, 9-13. http://dx.doi.org/10.1016/j.cvdpc.2010.11.001

[3] World Health Organization (2002) The World Health Report 2002. Reducing Risks, Promoting Healthy Life. World Health Organization, Geneva. http://apps.who.int/iris/bitstream/10665/42510/1/WHR_2002.pdf

[4] WHO (2013) Regional Overview on Hypertension in WHO Report on the Regional Consultation on Hypertension Prevention and Control.

http://www.searo.who.int/entity/world_health_day/leaflet_burden_hbp_whd2013.pdf

[5] Mendis, S., Puska, P. and Norrving, B., Eds. (2011) Global Atlas on Cardiovascular Disease Prevention and Control. World Health Organization, Geneva, Switzerland.

[6] Lim, S.S., Vos, T., Flaxman, A.D., Danaei, G., Shibuya, K. and Adair-Rohani, H. (2012) A Comparative Risk Assessment of Burden of Disease and Injury Attributable to 67 Risk Factors and Risk Factor Clusters in 21 Regions, 1990-2010: A Systematic Analysis for the Global Burden of Disease Study. The Lancet, 380, 2224-2260. http://dx.doi.org/10.1016/S0140-6736(12)61766-8

[7] CDC (2011) Vital Signs: Prevalence, Treatment, and Control of Hypertension-United States, 1999-2002 and 2005-2008. MMWR, 60, 103-108.

[8] Osuala, E.O., Oluwatosin, O.A. and Kadiri, S. (2014) Knowledge, Attitude to Hypertension and Lifestyle Habits of Rural Dwellers in Owerre-Nkwoji, Imo State, Nigeria. Journal of Public Health and Epidemiology, 6, 48-51.

[9] Okeahialam, B., Ogbonna, C., Otokwula, A., Joseph, D., Chuhwak, E. and Isiguzoro, I. (2012) Cardiovascular Epidemiological Transition in a Rural Habitat of Nigeria: The Case of Mangu Local Government Area. West African Journal of Medicine, 31, 14-18.

[10] Salako, B.L. (2011) The Romance of a Silent Killer: Equal Love and Hatred for All. An Inaugural Lecture, at University of Ibadan. Ibadan University Press.

[11] FRON (2007) Population Census. Federal Republic of Nigeria Official Gazette 24:94. Federal Government Printer, Lagos.

[12] Akpa, M.R., Emem-Chioma, P.C. and Odia, O.J. (2008) Current Epidemiology of Hypertension in Port Harcourt Metropolis, Rivers State, Nigeria. Port Harcourt Medical Journal 2, 218-223. http://dx.doi.org/10.4314/phmedj.v2i3.38922

[13] Osuala, E.O., Oluwatosin, O.A. and Kadiri, S. (2014). Knowledge, Attitude to Hypertension and Lifestyle Habits of Rural Dwellers in Owerre-Nkwoji, Imo State, Nigeria. Journal of Public Health and Epidemiology, 6, 48-51. http://dx.doi.org/10.5897/JPHE2013.0596

[14] Ike, S.O., Aniebue, P.N. and Aniebue, U.U. (2010) Knowledge, Perception and Practices of Lifestyle-Modification Measures among Adult Hypertensive in Nigeria. Royal Society of Tropical Medicine and Hygiene, 104, 55-60. http://dx.doi.org/10.1016/j.trstmh.2009.07.029

[15] Ataklte, F., Erquo, S., Kaptoge, S., Taye, B., Echouffe-Tcheugu, J. and Kengne, A.P. (2014) Burden of Undiagnosed Hypertension in Sub-Saharan Africa: A Systematic Review and 
Meta-Analysis. Hypertensionaha, 11, 114.

[16] Ford, C.D. and Kim, M.J. (2009) Perceptions of Hypertension and Contributing Personal and Environmental Factors among Rural South African Women. Ethnicity \& Disease, 19, 407-413

[17] Ige, O.K., Owoaje, E.T. and Adebiyi, O.A. (2013) Non-Communicable Disease and Risky Behavior in an Urban University Community in Nigeria. African Health Sciences, 13, 6267.

[18] Katarzyna, S., Michał, S., Iwona, J., Marek, P., Agnieszka, Z. and Jadwiga, D. (2011) Hypertension-The Silent Killer. Journal of Pre-Clinical and Clinical Research, 5, 43-46. http://www.jpccr.eu

[19] Aghaji, M.N. (2008) Hypertension and Risk Factors among Traders in Enugu, Nigeria. Journal of College of Medicine, 13, 114-115.

[20] Iyalomhe, G.B.S. and Iyalomhe, S.I. (2010) Hypertension-Related Knowledge, Attitude, and Lifestyle Practices among Hypertensive in Sub-Urban Nigerian Community. Journal of Public Health Epidemiology, 2, 71-77.

[21] American Heart Association (2013) Heart and Stroke Statistical Update. Ciculation, 127, e6-e245.

[22] Osuala, E.O. and Oluwatosin, A.O. (2014) Lifestyle Modification: Current Approach to Hypertension Prevention and Control. International Journal of Medicine and Health Profession Research, 1, 39-46.

[23] Oluwatosin, A. (2005) Focus Group Discussion: An Essential Tool in Community Health Nursing Research. West African Journal of Nursing, 16, 30-35.

http://dx.doi.org/10.1002/pon.4158

[24] Adedemeji, A.A., Lounsbury, D., Popoola, O., Asuzu, C., Lawal, A., Oladoyin, V., Crifase, C. Agalliu, I., Shankar, V. and Adebiyi, A. (2016) Improving Outcomes in Cancer Diagnosis, Prevention and Control: Barriers, Facilitators and the Need for Health Literacy in Ibadan Nigeria. Psychooncology, 5, 24. 


\section{Appendix 1: Focus Group Discussion Guide}

Discussion guide was drawn from the following subheadings:

-Knowledge of risk factors, symptoms, prevention, management, complications of hypertension Socio-cultural issues: Religious belief, gender ideology, traditional practices.

-Attitude towards risk factors, prevention, complications and likelihood of being a victim.

-Lifestyles of people in the community.

\section{Knowledge}

1. From your point of view, what is hypertension (Probe; what names do you call hypertension in this your town?)? Probe is used such as how do you know that a person is hypertensive?

2. Please what is your experience in your town concerning hypertension as regards occurrence, management etc.?

\section{Socio-cultural issues}

3. What do you think are the socio cultural issues linked to hypertension in this community?

Cues as age, education, occupation, and events could be used in the probe e.g. what can you tell us about age in relation to hypertension?

\section{Attitude}

4. How do you see this disease-hypertension (Please may we share your feelings, opinion and beliefs about hypertension?)?

\section{Lifestyles}

5. What do you know about lifestyle in relation to hypertension?

6. What practices or activities do you think can bring about rise in one's blood pressure?

\section{Suggestions}

7. What are your suggestions concerning prevention and control of hypertension in Isunjaba as a whole? 
Submit or recommend next manuscript to SCIRP and we will provide best service for you:

Accepting pre-submission inquiries through Email, Facebook, LinkedIn, Twitter, etc. A wide selection of journals (inclusive of 9 subjects, more than 200 journals)

Providing 24-hour high-quality service

User-friendly online submission system

Fair and swift peer-review system

Efficient typesetting and proofreading procedure

Display of the result of downloads and visits, as well as the number of cited articles

Maximum dissemination of your research work

Submit your manuscript at: http://papersubmission.scirp.org/

Or contact health@scirp.org 